\title{
Introducing: Queer Theory (in Three Shorts)
}

https://doi.org/10.51897/interalia/DVHI6885

Tomasz Basiuk

University of Warsaw

ORCID: 0000-0001-6637-6105

\begin{abstract}
Antke Antek Engel, member of the editorial board of InterAlia, co-operated with Filmfetch (Magda Wystub; Tali Tiller) and FernUniversität Hagen to create three educational films which discuss the tenets of queer theory in a manner suitable for non-academic viewers. The films were released in 2021 and are available on the university's website:

https://e.feu.de/queer-theory-videos

and on Youtube:

https://Www.youtube.com/channel/UCh98rBDWATF6bkxKNvpR4gQ
\end{abstract}

The three shorts, which are jointly titled Bodies, Figurations, Worlds: Video Introductions to Queer Theory are dialogues among three main characters dressed in close to primary-colored, strangely shaped costumes decorated with various appendages. These characters are U-M/M-U (Saboura Naqshband), who wears a reddish costume and sometimes a cone-shaped hat, KI-WI (Neo Huelcker), shaped like an oversized blueberry and dressed in blue, and TAM* (Pasquale Virginie Rotter), wearing a yellow costume shaped like a magnetic audio cassette. They are a cross between the animal-shaped or amorphic dolls of Sesame Street, or perhaps Teletubbies, and the bigger-than-life gods of the Greek Olympus. These characters' powers include being shapeshifters, for example, U-M/M-U has various pendants added to their costume in "Bodies," while in "Worlds" the three characters are transformed, respectively, into CONE, BALL, and JAGGED SHAPE. The transformation of TAM* into JAGGED SHAPE is especially dramatic, as the magnetic tape gives way to two brightly shining CDs worn in the manner of spectacles. In each episode, these characters interact not just with each other but also with SQUARE BRACKET (Magda Wystub) and with CURLY BRACKET (Antke A. Engel and Jayrôme C. Robinet), and in "Figurations," with a picture by the American artist Laylah Ali, known for depicting ambiguous race relations with comic-strip like figures. While SQUARE BRACKET presents as moving lips colored purple, reminiscent of Tim Curry's lip-synching in the opening sequence of the camp classic The Rocky Horror Picture Show (1975), CURLY BRACKET is a Janus-faced creature who tightens its two bowstrings, like a two-faced Eros, to underscore a point being made or when offering a discursive intervention. Both BRACKETS, but especially the CURLY BRACKET, act as chora to the more Olympian figures occupying centerstage. Robinet additionally performs as herself/ himself in extended, very effective soliloquies in "Bodies" and in "World," commenting on gender performativity in speech and body language. 
All three shorts are very proficient at introducing a range of theoretical perspectives not easily brought together in a relatively brief introduction. Desire, performativity, intersectionality, cyborg, resignification, heteronormativity and homonationalism are among the terms invoked and elucidated in these films. Desire occupies a special place because it is presented as the spiritus movens behind the various normative orderings of sexuality and gender - as desire is defined in terms of the duality between the desiring subject and the object choice, determining, for example, the distinction between homo- and heterosexuality - while it is also the agent capable of motivating resistance against these norms, a transgressive force. However, at the end of each episode pleasure rather than desire is invoked with a line spoken by Engel in voice-over, "Pleasure in complexity, confusion and conflict that's queer," which at the end of "Worlds" becomes, "Pleasure in complexity, confusion and contact in conflict - that's queer." This emphasis on pleasure (and on contact) arguably de-centers desire and offers an alternative way of imagining queer as not just a discursive formation (with desire implicitly understood to be an effect of language) but in terms of bodily experience. Body language is responsible for eighty percent of communication, a character notes, and this should make us hopeful about the effectiveness of drag, a campy version of which we find ourselves watching in these films.

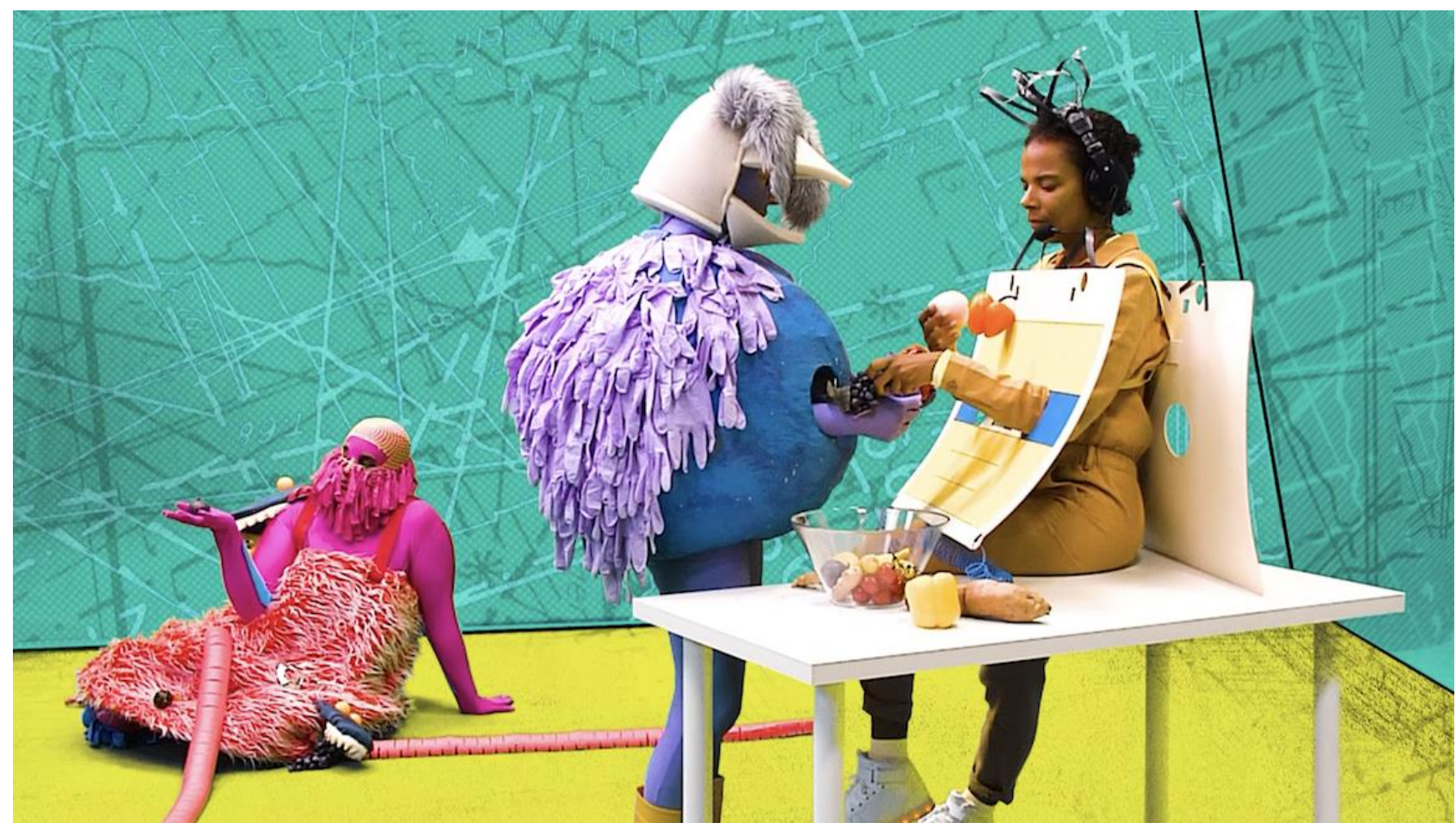

Video Introductions to Queer Theory (Engel and Filmfetch, FernUni Hagen 2021).

A deliberate focus on complexity, confusion and conflict is a way of ensuring that queer theory does not get reduced to a set of simplistic assertions. Queer theory is discussed in the films as, on the one hand, invested in an anti-homophobic, anti-transphobic, and broadly anti-discriminatory agenda; on the other, it is shown as subverting the very identity categories whose ideological function is to struggle against discrimination. On the one hand, a Deleuzian perspective within queer theory posits desire as endlessly productive; on the other, a nuanced understanding of intersectionality inevitably 
complicates single-issue politics of sexuality and gender by looking to race, class, and other analytical categories. As is perhaps especially the case of trans* theorizing and activism, both access to identity categories and their questioning are central to the intellectual and the political agenda.

Despite some (necessary) repetition and a general similarity of tone and style, each film has its own intellectual focus and its own characteristic aesthetic. "Bodies," the longest of the three (at ca. 20 minutes) is the only one to be subdivided into chapters titled, for example, "Doing Sex_Gender" and "Gender Vertigo." Bodies are represented by the costumes worn by characters, to which other characters append various bits, and by Robinet's queerly performing body positioned in the middle of street traffic. In "Figurations," emphasis is laid on images and on the manner in which media create, rather than merely represent, reality. An image of a kissing pair by Laylah Ali is first an object of a debate among the characters and then it, too, becomes a speaking character, somewhat in the manner of Horace's ut pictura poesis. The image is discussed in terms of the relationship to which it invites the viewer by presenting its two figures against an empty, blank background and by having them turn their gaze toward the viewer and away from the frame. The viewer is thus co-constructing the world imagined in the work rather than merely observing it from a safe distance. In "Worlds," the characters are first submerged under the sea and later find themselves in outdoor spaces, as emphasis is placed not just on "worlding," that is, the emergence of a world, or worlds, but on the mutual co-dependence of agents and their surroundings. "Differences are more complex than binaries," a voice-over lets us know early on, and the film has a definite ecological spin to it, as a call for "inter-action" is replaced with a call for "intra-action," and as "sympoesis, not autopoesis" is indicated as the preferred mode of worlding.

This short series of films is a very recommendable introduction to queer theory and a thoroughly enjoyable one at that. Shot in German, which testifies to the creators' popularizing ambition, the films have been given English subtitles and, on many occasions, English words and expressions are used amidst the German. ("Worlding" is cited as an example of a word which does not have a satisfactory German equivalent.) It would not be difficult to add subtitles in other languages, including Polish while Spanish subtitles already exist. Whatever the language version, these shorts are worth recommending to both the young and the old. 